Espacio, Tiempo y Forma, S. III, H. ${ }^{a}$ Medieval, t. 4, 1991, págs. 13-41

\title{
Fuentes históricas abulenses en la Baja Edad Media
}

\author{
Blas CASAdo QuintanilLa
}

Ávila no es una isla dentro de Castilla; la documentación recibida en su concejo o emanada de esta institución o de otras instancias, no podrá tener otras características peculiares o distintas a las de otras ciudades del reino castellano en lo que hace referencia a la tipología de las fuentes; la peculiaridad vendría dada por el contenido de las mismas, derivada de condicionantes muy concretos de población y espacio geográfico o de la especificidad de algunas personas destacadas. Sorprende, sin embargo, la existencia de una fuente histórica especifica, de una Crónica de la población de Ávila en la que aparecen abundantes noticias acerca de los primeros pobladores de esta ciudad y su Tierra después de la conquista por parte de los cristianos del norte.

El planteamiento precedente nos permite organizar esta exposición en dos apartados: uno, dedicado a las fuentes bajo medievales en general, dentro de las cuales hay que encuadrar las de Ávila; otro, a dar noticia puntual de las fuentes abuienses en la Baja Edad Media, en particular.

\section{FUENTES MEDIEVALES}

Podríamos comenzar este estudio recapitulando las distintas definiciones de fuentes históricas aportadas por Bauer, Topolski, Riu, Fasoli, Vicens, Febvre, Genicot y otros; o las distintas actitudes ante las fuentes organizadas en torno al positivismo, al materialismo histórico, al sociolo- 
gismo o a la escuela de los annales. Siendo esto importante, no lo creemos necesario y cae fuera de nuestro actual objetivo.

Para poder enfrentarnos con éxito a las fuentes históricas se hace necesario determinar su ampiidad, su tipología y sus exigencias. La fuente histórica medieval, por excelencia, son los textos. Pero en palabras de Febvre: «todos los textos, no sólo los documentos de archivo... también un poema, un cuadro, un drama son para nosotros documentos, testimonios de una historia viva humana, saturados de pensamientos y de acción en potencia...” ' . Añadamos que estos textos, estos documentos, aún los más claros en apariencia y los más complacientes, no hablan si no se sabe interrogarlos. Dejando a un lado la actitud historiográfica adoptada, esto es, con independencia de las distintas formas de concebir y de escribir las historia, hemos de partir de las coordenadas señaladas: "todos los textos" y "saber interrogarlos", si pretendemos acertar en el conocimiento de nuestro pasado.

\subsection{Algunas características de las fuentes medievales}

Las fuentes históricas en la Edad Media reúnen una serie de características cuyo conocimiento puede ahorrarnos algunas ansiedades y no pocos disgustos. La diversidad de los centros expedidores de documentos: la corte y además ambulante, los concejos, los monasterios, las catedrales, los señoríos..., facilitan la dispensión en el momento de su producción; la inercia, la fragilidad del soporte material, los abatares históricos no sólo bélicos sino también legislativos, la desaparición o concentración de algunos centros emisores, dificultan la localización de las fuentes históricas, en caso de que aún se conserven.

El laconismo y la escasez de documentos en la Alta Edad Media contrasta con una mayor abundancia cuantitativa y cualitativa de documentos de archivo, crónicas, manifestaciones artísticas y literarias, de la Baja Edad Media. Estaríamos cerca de la verdad si afirmáramos que en los tiempos altomedievales la producción documental en general fue muy escasa; será necesario, no obstante, acudir a la explicación, no por muy conocida, menos acertada: la destrucción, la pérdida voluntaria e involuntaria de muchos textos medievales.

\footnotetext{
1 Febvre, Lucien, Combates por la Historia. Barcelona 1975, pág. 29.
} 
Pérdida o destrucción involuntaria favorecida por la fragilidad de la materia escriptoria, por la vida poco monótona y llena de inseguridades, de pequeñas y continuas batallas... causas todas ellas poco favorables para la conservación de la vida humana y de sus manifestaciones. Pérdida o destrucción voluntaria porque una de las características peculiares de todo diploma radica en su carácter jurídico: los documentos debían estar acomodados a la legislación vigente. El cambio de esta legislación, la mutación o desaparición de uno de los participantes en los documentos «inter vivos» $u$ otras razones similares a estas, hacian inútil su conservación o se convertían en documentos condenados al olvido, salvo en aquellos casos en que el aludido escrito se tranformara en un título de propiedad de una heredad o de cualquier otro tipo de bien estimable. Esta mentalidad de posible inutilidad de los documentos es intensa en la época altomedieval y perdura a lo largo de toda la Edad Media. Podemos recordar una de las manifestaciones más conocidas. Cada vez que cambiaba el rey, las personas o instituciones acudian a la cancillería del nuevo rey para que este confirmara, esto es, expidiese con su firma y autoridad el documento emanado de la cancillería de su predecesor. Se afirmaba por esta vía la necesidad de mantener la utilidad de un diploma regio que pudiera caer en el campo de la inutilidad de no superar, a su debido tiempo, la inspección de la nueva cancillería real y su ulterior «vidimus» y validación.

Otro de los aspectos a destacar en relación con las fuentes históricas que nos ocupan es la unilateralidad de su origen. Ello condiciona su fiabilidad y obliga al historiador a actuar con suma cautela a la hora de valorar unos testimonios lastrados por la parcialidad, que no mendacidad, de los intereses de los informantes. En palabras de Genicot «hasta la Baja Edad Media la mayor parte de las fuentes tienen un origen clerical y este hecho influye una vez más en su representatividad y sobre la significación de sus aserciones y de sus silencios" ${ }^{2}$. En esta misma línea Ruiz de la Peña ${ }^{3}$ da un paso más e indica que ala exclusiva vinculación de la producción historiográfica y diplomática, hasta época muy avanzada del Medievo, a los círculos dominantes eclesiásticos y laicos debe ser tenido en cuenta como factor corrector de los desequilibrios informativos sobre ciertos sectores sociales y aspectos vitales del mundo medieval's.

Esta unilateralidad de las fuentes históricas puede sustentarse en una base psicológica, social o político-religiosa, cuya proyección histórica

\footnotetext{
2 Introduction, fasc. 1 de la Tipologie..., Universitè Catholique de Louvaine. BrepolsTurnhout 1972, pág. 9.

${ }_{3}$ RuIz de LA PEÑA, Introducción al estudio de la Edad Media. Madrid 1984, pág. 265.
} 
puede explicarse de varias formas; bastaría con releer algunas interpretaciones históricas, más o menos alejadas de nosotros en el tiempo, para constatarlo. No es tiempo ni lugar para hacer realidad un estudio tan amplio. Sólo pretendemos ahora presentar unas notas en torno a las fuentes históricas medievales.

Cabe hablar, por ello, de lo que el Profesor Benito Ruano ha llamado "La Alteridad en la Historia» ", alteridad que puede entenderse como "la identidad del otro". Este planteamiento supone el establecimiento de una relación dialéctica entre ambos sujetos de la historia: «el uno» y «el otro", entendiendo por sujetos de la historia, no sólo a los individuos, sino también, y a veces de forma preferente, a los grupos sociales y de interés. La unilateralidad de las fuentes históricas se manifiesta con claridad si tenemos por válidas las palabras de Benito Ruano, quien afirma que «la actitud natural del "uno" es la de neutralizar, absorber o superar al "otro"» 5 , lo que a la postre supone prefabricar una imagen del "otro". Sería inútil olvidar que el que fabrica una imagen «del otro», si tiene medios, procurará, por distintas maneras, hacer a los demás partícipes de sus propias convicciones e ideas. En el extremo contrario de la relación, «el otro», si pudiera, haría lo mismo "del uno», pero le faltarán medios para extender su imagen «del uno».

La imagen creada por "el uno", a quien vamos a llamar autor individual $u$ organismo encargado de preparar y expedir los documentos, estará mediatizada, aunque sea involuntariamente, y así se transmitirá a los destinatarios de esa documentación y a los historiadores. En esta línea, la documentación concejil abulense y no abulense, delata la existencia, de una parte, de unos estamentos en tensión, y de otra parte la existencia de unos cristianos, de unos moros y de unos judíos cuya coexistencia goza de buenos momentos y de otros que algunos de ellos no quisieran recordar.

En cada documento de archivo podemos distinguir a un autor y a un destinatario, beneficiado o perjudicado. Siempre hay un «uno», individual o colectivo, que ostenta autoridad, que puede coincidir con el autor o titular del documento o con el rogatorio o escribano; aparte existe un "otro» que acepta de buen o de mal grado el contenido jurídico del documento. En manos del primero está el diploma en su conjunto, incluido el formulario conforme al cual se realiza la conscriptio; sólo una cláu-

4 Benito Ruano, Eloy, De la Alteridad en la Historia. Discruso leido al día 22 de mayo de 1988 en la recepción pública de Don... Madrid, Real Academia de la Historia, 1988.

5 Ibidem, pág. 17. 
sula, cuando existe, puede servir de medio de expresión para el segundo, quien no siempre coincide con el titular del documento, especialmente en los contratos «inter vivos» altomedievales, y esta es la cláusula expositiva. Contiene esta cláusula los motivos por los que el que suscribe expide el documento, motivos, en general, alegados por el destinatario y asumidos por el titular. Incluso esta cláusula que no es sino un resumen de la demanda del otro, está redactada según la visión del que dicta o escribe.

Para no asumir, ni siquiera inconscientemente, la unilateralidad provocada por la alteridad, esto es, por la imagen que el «uno» transmite del "otro" a través de sus documentos, nos vemos obligados a leerlos y releerlos y tratar de adentrarnos en profundidad en su significado claro y manifiesto en ocasiones y no tan claro ni manifiesto en la mayoría de los casos.

En este sentido y hablando de la evolución de las mentalidades en la época que nos ocupa, el Profesor Martín Rodríguez en un trabajo sobre los documentos del monasterio de Trianos (León) en el siglo $\mathrm{XII}^{6}$ estudia dos cláusulas diplomáticas: la invocación y la sanción.

Sobre la cláusula de la invocación afirma: «en cerca del $60 \%$ de los casos, la divinidad está presente de forma explícita desde el comienzo del documento, dato que confiesa algo de todos sabido: la sociedad del siglo XII es una sociedad profundamente religiosa; aunque menos de lo que tradicionalmente se cree si hemos de hacer caso del $39 \%$ restante de ausencias, cuyo significado se acrecienta al observar que Dios desaparece en 16 documentos reales y en siete dirigidos o redactados en el monasterio de Trianos. Lógicamente, continúa, este dato no nos permite hablar de increencia en los grupos dirigentes de la sociedad, pero quizá no sea aventurado suponer en los notarios reales y monásticos un deseo, consciente o inconsciente de no mezclar la divinidad en negocios civiles". Siguiendo su investigación y respecto de las cláusulas penales afirma: "la evolución, el paso de una sociedad en la que la religión lo es todo a otra en que cada vez tiene más fuerzas los aspecto civiles se observa con relativa claridad en las cláusulas penales... la forma de expresar la

\footnotetext{
"MARTín, José Luis, "Utilidad de las fórmulas "inútiles" de los documentos medievales", en Semana de Historia del monacato Cantabro-Astur-Leonés. Monasterio de San Pelayo, 1982, págs. 81-86.

Idem., "Feudalismo y Mentalidades", en En torno al feudalismo hispánico. Madrid, Fundación Sánchez Albornoz, 1989, págs. 23-40.
} 
sanción divina y canónica y, lógicamente, la imagen que se tiene de Dios varía considerablemente según las épocas».

\subsection{La escritura}

Esta unilateralidad de la documentación altomedieval se reduce bastante en los siglos bajomedievales, o al menos, toma otra variante. El renacimiento del siglo XII y XIII, la aparición de los burgos, el comercio de algunos excedentes agrarios, el comercio marítimo incipiente, el asentamiento de las Universidades... se produce una ampliación del conocimiento y utilización de la escritura, se amplía el número de personas que conocen y ejercen el arte de escribir y se generaliza el notariado urbano y villano. Así, aquella unilateralidad de la que hablábamos anteriormente, ya no es tanto eclesiástica cuanto social, porque son muy pocos los que saben escribir y por lo mismo dejar constancia de sus propios intereses y sentimientos. Con todo, la escritura, considerada en sí misma como un elemento más de la cultura del pasado, y no simplemente como vehículo de transmisión de noticias, durante los siglos citados, se ha cursivizado, se ha hecho menos adecuada a unas pautas librarias para convertirse en una manifestación de una cultura. Aunque se mantiene una preciosa letra de códices, hasta el siglo XIV se podía hablar de una nomenclatura paleográfica que respondía a unos cánones bien delimitados: visigóticomozárabe, carolina, gótica. A partir de esta fecha ya no se podrá aplicar una tipología paleográfica rígida, pues al ser la escritura patrimonio de muchas personas y cultivarse en muy distintos centros emisores de documentos, unidos por la misma cultura y separados por sus funciones, comienza a personalizarse, hasta llegar a la letra utilizada por los escribanos en los procesos judiciales o en los mismos protocolos; la escritura de o entre particulares nos es menos conocida.

La escritura, siguiendo a Cenceti y a Petruci, ha sufrido una transformación similar en ritmo a la realizada por la propia sociedad; se ha convertido así en el reflejo de una nueva mentalidad social, efecto de una cultura.

\subsection{Documentación de archivo}

Las fuentes documentales, entendidas en sentido amplio y no sólo referido a los diplomas y cartas reales, han adquirido en la actualidad 
una gran importancia, desplazando el lugar preeminente a las fuentes narrativas, dejando, al mismo tiempo, a un lado la historiografía positivista y su tendencia a "venerar" los documentos y sus aserciones como claras y manifiestas a primera vista.

Al documento se le puede encuadrar dentro de las fuentes históricas "preterintencionales", lo que le confiere un grado de certeza mayor que el que ofrecen las fuentes narrativas, porque éstas intentan presentar una interpretación de los acontecimientos de que se ocupan. Los documentos permiten muchas veces rectificar errores de las fuentes narrativas y, sobre todo, nos introducen en el conocimiento de aspectos de la vida histórica prácticamente ausentes de las crónicas y de otras fuentes narrativas; sensu contrario, estas, como veremos, tienen otros valores históricos de los que carecen aquéllos.

Las cancillerías reales y la publicación de los diplomas de ellas emanados, han merecido la actividad casi exclusiva de muchos historiadores en detrimento de otros conjuntos documentales. Aquellos han compartido el lugar de privilegio junto con los fondos monásticos y catedralicios. Entre los condenados hasta no hace mucho al olvido encontramos los documentos de origen concejil y los de las casas nobiliarias en su época medieval.

Los documentos privados, manifestación escrita de las relaciones «inter vivos", entre particulares, ocupan un amplio espacio entre los fondos documentales de las catedrales y los monasterios debido a una relación con estas instituciones cuya aparición y permanencia estuvo ligada al sistema de economía feudal. La vinculación de los "escriptores" a los señores feudales en general, facilita la impregnación de esta cultura en los documentos redactados y escritos por aquéllos. El formulario conforme al que han de escribirse los contratos entre particulares, transmite en esencia la cultura del que lo hace y/o del que lo asume, a la vez que limita la presencia de las manifestaciones de las personas, individuos comunes, intervinientes en aquellos contratos.

Para beneficio de los historiadores, esta rigidez del formulario afecta de manera especial al protocolo inicial y final y a algunas cláusulas del texto del documento, no tanto a las cláusulas expositiva y dispositiva ${ }^{7}$. En ambas cláusulas, en las que se exponen los motivos por los que se llega a realizar el contrato y la resolución pertinente y concreta, dado que

\footnotetext{
7 VIOLANTE, Cincio, "Atti privatti e storia medievale", en Fonti e Studi del Corpus Membranarum Italicarum. Roma, II Centro di Ricerca, 1982, págs. 49-96.
} 
los actos a consignar son tan variados en el espacio y en el tiempo y las circunstancias personales son muy diversas, han de hacer acto de presencia estos condicionantes y por lo mismo, estas cláusulas han de alejarse del escrito formulario. Su redacción permite un lenguaje más fluido, más apegado a los intervinientes en el acto jurídico y más alejado del rogatorio. Ello facilita la aparición de precisiones de tipo social, cultura, religioso y económico; la introducción de vulgarismos, de sistemas de medidas, de fórmulas distintas de señalar los límites de las fincas y de describir las propiedades y las cosas, de apodos y otras calificaciones... que expresan con mayor fluidez la vida ordinaria de las personas de un determinado entorno.

\subsection{Fuentes narrativas}

Además de las fuentes de archivo, relativamente abundantes en lo que atañe a Ávila, contamos con las crónicas generales del reino de Castilla y una crónica cuya información se refiere a la reconstrucción de la ciudad y de su Tierra.

\subsubsection{Las Crónicas}

La crónica es en sustancia una descriptio temporum, concebida sobre todo para informar al lector de lo que llamaríamos la continuidad histórica y los ritmos de larga duración. Nos proporcionan el hilo conductor de los acontecimientos de largo alcance, hilo que se nos pierde en el análisis de los documentos de archivo que de ordinario hacen referencia a hechos puntuales. La crónica encierra una especial importancia para la investigación histórica, por cuanto en ella aparecen noticias recogidas de muy diversas fuentes, fuentes que en la actualidad se han perdido y que solo a través de las fuentes narrativas han llegado hasta nosotros.

En cada crónica aparecen los acontecimientos históricos ya pasados para el que escribe, sobre los cuales el propio autor hace su selección y vierte su ideología y preferencia por unos u otros personajes; a la vez se transmite el modo de vida, y el ambiente de la época en que le ha tocado vivir a su autor. La crónica se convierte, por esta vía, en instrumento transmisor voluntario y selectivo del pasado y en testimonio involuntario del presente del cronista.

En estas fuentes narrativas encontramos, en lugar bien destacado, las grandezas de los grandes actores de la historia, las ambiciones que 
flotan sobre los pueblos, arropados por un estilo y redacción literarios destacables en la mayoría de los casos; en un segundo o tercer plano, aparece la vida íntima del pueblo en general, sus vicisitudes sociales y su quehacer diario. A veces dejan constancia de las miserias de los tiempos de los que se ocupan, sin que este sea el objetivo que se ha propuesto el cronista.

Desde las primeras crónicas hasta las de últimás fechas medievales se produce una importante evolución. Las anteriores al siglo xili: Epitome Ovetense, Crónica Adefonsi Imperatoris, Crónicom mundi del Tudense, Crónica de Jiménez de Rada, Crónica Najerense están redactadas en latín con intervención directa de personas eclesiásticas.

Después de mediado el siglo XIII las crónicas, entre otras: Primera Crónica general de España, Crónica de SancholV, Crónica de Fernando $N, \ldots$ están redactadas en lengua vernácula y su autoría corresponde a personas eclesiásticas y seglares.

Las crónicas latinas se sitúan en la historia oficial, en la consabida alianza del trono y el altar. A partir de la Crónica General de España se incorporan con frecuencia noticias transmitidas por las epopeyas y se muestra alguna atención mayor a otros personajes ensalzados por los juglares. Las crónicas de finales del $\mathrm{XV}$ y del $\mathrm{XV}$ incluyen con mayor frecuencia abundantes documentos de archivo.

Esta tierra abulense tiene el privilegio de contar con una Crónica de la Población de Ávila en la que se nos proporcionan noticias acerca de los primeros pobladores de esta ciudad después de la conquista por los cristianos del norte. El conde Raimundo de Borgoña fue el repoblador. Comienza con el reinado de Alfonso VII y finaliza en tiempo de Alfonso X. No se conoce al autor del texto, ni la fecha de su redacción. Parece escrita por un caballero. Gómez-Moreno cree que se escribiría en torno a 1255; mientras que Amparo Hernando Segura, la coloca en 1256. Existen cuatro manuscritos de esta crónica: dos en la Biblioteca Nacional de Madrid y dos en la Biblioteca de la Academia de la Historia. La primera publicación la hizo Gómez-Moreno ${ }^{8}$ el año 1943 y la que yo he manejado la hizo Amparo Hernando Segura ${ }^{9}$ en 1966.

${ }^{8}$ Gomez-Moreno, M., Crónica..., BRAH, XCIII, I, págs. 11-56.

9 Hernando Segura, Amparo, Crónica.... Textos Medievales. Valencia, Universidad de Valencia, 1966. 


\subsubsection{Los Cantares de Gesta}

Personas destacadas de la historia de los pueblos ocupan un lugar preeminente en estas obras. Estos personajes están muy arraigados en la vida del pueblo, de la sociedad y por ello estos Cantares nos proporcionan noticias de unos aspectos más variopintos de una época en la que la historia oficial cuenta con otros cauces distintos de comunicación.

\subsubsection{Relatos de Viajes}

El interés histórico de estas obras está relacionado con las abundantes descripciones de lugares, costumbres de las personas y los pueblos, formas y medios de vida, fiestas locales,...

\subsubsection{Hagiografías}

Las Vidas de Santos, con narraciones de sus correspondientes vida, milagros y hechos prodigiosos, traslado y veneración de reliquias, son un extraordinario reflejo de la religiosidad popular que en parte condiciona y explica muchos aspectos de la vida de las comunidades a las que afecta. Será necesario buscar con cautela lo histórico y separarlo de lo fabuloso. En cualquier caso es un buen camino para el conocimiento de la historia de las mentalidades, de la que hoy se ocupan tantos especialistas.

\subsubsection{Textos literarios}

Los textos literarios en general son una fuente de extraordinario valor histórico sobre todo para el conocimiento de dos aspectos del pasado: las mentalidades y la situación social. Se ha dicho que el escritor es una persona con una sensibilidad especial para captar las preocupaciones de su tiempo y transmitirlas a través de sus escritos. La variedad de puntos de interés en el quehacer de los grupos humanos, grandes o pequeños, permita a los escritores poner de manifiesto las contradicciones internas de una sociedad cuya vida transcurre en medio de tensiones de orden económico, religioso o social.

\subsection{La Arqueologia}

No tenemos la intención de olvidar las fuentes arqueológicas, la llamada cultura material, aunque compartimos la opinión de P. Chaunu para 
quien «sin miedo a ser desmentidos por el porvenir, la historia permanecerá en lo esencial tributaria de lo escrito: por eso lo que nosotros podemos esperar mejorar depende de una mejor lectura, de un tratamiento más elaborado del dato primito» ${ }^{10}$.

Hasta no hace mucho tiempo se consideraba que los resultados de las excavaciones arqueológicas eran de gran utilidad para aquellas épocas históricas y zonas geográficas de culturas periféricas de África y de Asia, en las que no existian o se carecía de fuentes escritas suficientes. En la actualidad los resultados de las excavaciones arqueológicas son considerados como una fuente importante para fijar, con relativa precisión, determinadas cuestiones del acontecer histórico. A su favor juega el valor de ser considerada como una fuente histórica «preterintencional» o de restos a los que de ninguna manera se les puede encuadrar bajo el epígrafe de actividad intencionada para «curiosidad» de posibles investigadores, salvo intervención de falsarios. Por medio de los trabajos de investigación arqueológica, ordinariamente ligados a poblaciones desiertas o abandonadas, y con grandes dificultades de todo tipo en zonas pobladas actualmente, se pueden descubrir las vicisitudes del habitat humano y sus mutaciones, asi como aspectos materiales de civilizaciones pasadas que de otra forma se nos escaparían.

El método de irivestigación arqueológico de estar estrechamente vinculado a la prehistoria, esto es, a una época en la que la ausencia total de documentación escrita no permite otra vía de conocimiento, ha pasado o ha penetrado en el campo de la investigación de la historia antigua y medieval. Es evidente que la ayuda que la Arqueología puede prestar a la investigación en la antigüedad y en la época medieval es sustancial en aquellos temas para los que se cuenta con restos materiales abundantes, mientras que los documentos escritos son escasos, cuantitativa y cualitativamente o su laconismo produce más ansiedades que alegrías al investigador. En este supuesto siempre nos encontraremos con una situación un tanto molesta para el historiador; los propios arqueólogos advierten que sus dataciones son relativas, con una oscilación en años, arriba o abajo, en cuantía variable, que resulta inapropiada para centrar una secuencia de acontecimientos. Así, en palabras del Profesor Sayas Bengoechea «se han realizado muchas excavaciones de Villae, sobre todo en la parte correspondiente a la residencia del dueño. De estas excavaciones proceden numerosos objetos agrícolas y otros, susceptibles

10 Chaunu, P., «¿Es necesario privilegiar una determinada forma de Historia?», en El Método Histórico, Pamplona, Universidad de Navarra, 1974, pág. 38. 
de interpretación económica, pero, fuera de su contabilidad minuciosa, de su descripción y de las intuitivas y vagas generalizaciones económicas subsidiarias, poca luz se proyecta acerca de la forma de explotación del suelo, de la organización del trabajo, de la estratificación social..." ${ }^{11}$.

\subsection{El Arte}

El arte en general y la pintura y miniaturas en particular son una fuente histórica menos atendida por los historiadores, aunque de ello se ocupan y con éxito los historiadores del arte. Éstos cuentan con un tipo documental privilegiado: la obra de arte. Cuando ella se conserva, el estudio minucioso de la misma, deja en segundo plano cualquier tipo de documento sobre la obra en sí; otra cosa será buscar los datos de archivo que expliquen ciertos procesos de elaboración artística, el soporte económico, el trabajo y los trabajadores y hasta las motivaciones que dieron como resultado la obra que se contempla. Cuando falta la obra, bien porque sólo se llegó al proyecto, bien porque se ha destruido el edificio, las aportaciones documentales gráficas: trazas, dibujos..., contratos, actas y acuerdos de las autoridades competentes sobre esta o aquella obra, pasan a ser el único camino viable para el investigador. Por tratarse de un marco abulense quiero recordar unas palabras de GoMEZMORENo, ${ }^{12}$ una interpretación histórica a partir de la arquitectura de la Moraña, esto es, del Mudejar abulense, sobre la que escribe to siguiente: «Es una arquitectura impuesta por la naturaleza del suelo, arquitectura popular, semimoruna o semicristiana, reflejo de la vida nacional frente al elemento avasallador francés apadrinado por la corte y por los monjes, que representa la arquitectura románica y ojival. Arquitectura Mudejar menospreciada y sin estudiar todavía... (Cuando Gómez-Moreno escribía esto aún no se había celebrado los tres simposios internacionales sobre el mudejarismo en Teruel ri se habian publicado sus actas)... así, continúa el autor, las ciudades se enorgullecen con sus monumentos de piedra: catedrales, conventos, iglesias aristocráticas, debidas, no a las conveniencias e iniciativa del pueblo y del bajo clero que las atiende, sino a las rentas de una corporación, a las prodigalidades de un rey, a las larguezas que, a cuenta de sufragios y en descargo de sus conciencias,

11 SAYAs Bengochea, J. J., "Arqueología e Historia Antigua», en A Distancia. Universidad Nacional de Educación a Distancia, junio 1989, pág. 20.

12 Gómez Moreno, Manuel, Catálogo Monumental de la Provincia de Ávila, III, (1983), págs. 223-224. 
otorgaban los ricos y los señores. El pueblo había de contentarse con poco, ahorrando todo lo posible su esfuerzo y sus dispendios, como que su fuente de ingresos era el trabajo, no saqueos y opresiones; él no podía traer materiales de grandes distancias ni labrarlas con primor, no podía hacer venir arquitectos famosos; tampoco el pechero de entonces sabía gran cosa de ciertas artes... en vez de piedra de sillería, empleaba los materiales ordinarios del país; en vez de edificios según el patrón francés, dejaba al moro mudejar que se las compusiera a su gusto».

\section{COLECCIÓN «FUENTES HISTÓRICAS ABULENSES»}

La Institución de Estudios Locales "Gran Duque de Alba", dependiente de la Diputación Provincial de Ávila y del CSIC, con la colaboración económica de la Caja de Ahorros de Ávila, ha emprendido hace pocos años la tarea de la publicación de la documentación de archivo correspondientes a la Edad Media existentes en el ámbito provincial. Hasta el presente son varios los volúmenes publicados y otros aún están en preparación. Entre estos últimos en preparación creo de interés destacar el segundo volumen de la documentación concejil de Ávila y un catálogo de los protocolos notariales de finales del siglo $\mathrm{XV}$ y primeros años del XVI a los que después dedicaremos nuestra atención. Ahora, siguiendo la numeración de los volúmenes dentro de la colección, haremos un pequeño comentario de cada uno de ellos.

\subsection{Archivos civiles}

Dividiremos en dos grupos los volúmenes sobre fuentes históricas publicados hasta ahora por razón de su habitual denominación: civiles y eclesiásticos.

Barrios García, Ángel; Casado Quintanilla, Blas; Luis López, Carmelo; Ser QuiJano, Gregorio del, Documentación del archivo municipal de Ávila. Ávila 1989.

Cuando comenzamos la transcripción de los documentos de archivo del concejo abulense nos dimos cuenta de que, sino completamente ol- 
vidada, no se podía ciertamente hablar de unos fondos bien conocidos por los historiadores. En esta primera parte transcribimos un total de 107 piezas documentales. El más antiguo de los conservados es un privilegio de Alfonso $X$ de 1256 , original y en pergamino, por el que este monarca concede numerosas franquicias y exenciones a los caballeros de la ciudad de Ávila. Cierra este volumen una carta de Isabel la Católica de diciembre de 1474 por la que anuncia al concejo la muerte de su hermano y su acceso al trono castellano.

La tipología de la documentación de archivo recogida en este primer volumen queda enmarcada dentro de lo que es habitual en la época: privilegios reales, confirmaciones, sentencias judiciales, cartas de censo, contratos, deslindes, procuraciones, repartimientos. Conviene señalar la escasez de originales conservados y la poca presencia de pergaminos como soporte material de los documentos. La gran mayoría son copias en confirmaciones, traslados o recopilaciones posteriores a la fecha de su expedición. La explicación de esta escasez de originales hemos de buscarla en un acontecimiento bélico: según una copia de mediados del siglo XVIII de un diploma de Juan I, los documentos del concejo abulense fueron destruidos el año 1368 con motivo del incendio "en unas casas que heran en el arrabal de la dicha ziudad, a do estavan en guarda, al tiempo que los ingleses entraron en Castilla con don Pedro" (AHPA. Sección Ayuntamiento. Leg. 4, núm. 15).

Los documentos aquí transcritos nos informan sobre el proceso de consolidación de los caballeros villanos en Ávila, gracias a las sucesivas prerrogativas que van arrancando del poder regio; del fenómeno de usurpación de propiedades comunales realizado por algunos miembros de la fracción dominante en el concejo, desviándolas del disfrute de todos los vecinos de la villa y tierra de Ávila, actuación que da ocasión a una serie de actuaciones judiciales para intentar volver las cosas a sus cauces originarios; también aparecen dos documentos referidos al rey Alfonso de Ávila que son un exponente de apoyo prestado por el concejo abulense; cabe reseñar, asimismo, la serie de recompesas y promesas que se contienen en las cartas de la princesa Isabel, después reina Católica, buen exponente de la posición adoptada por esta ciudad en la compleja sucesión de Enrique IV; las cartas sobre nombramiento de escribano público $y$ aumento de sueldo de algunos oficiales del concejo.

También los temas ausentes revisten cierta importancia, asi: la inexistencia en la misma de menciones a bandos o linajes en la gestión de la administración concejil. No se transcriben aquí las ordenanzas de la ciudad, porque han merecido una publicación aparte dentro de esta misma colección. 
Ser QuiJano, Gregorio del, Documentación medieval del archivo municipal de San Bartolomé de Pinares. (Ávila). Ávila 1987.

El propio autor de este volumen, el Profesor Gregorio del Ser Quijano, justifica en su introducción las causas que le empujaron a transcribir esta documentación: «me pareció más oportuno elegir fuentes de origen civil y de carácter municipal que no las de otras características o procedentes de instituciones religiosas... a la vista de la situación en que se encuentran los trabajos sobre documentación medieval abulense. Si se hace un repaso, por rápido que sea, a lo realizado hasta ahora, se constata, junto a una notable dispersión, un claro predominio, tanto en amplitud como en calidad, de las investigaciones sobre documentación conservada en grandes archivos y de procedencia religiosa frente a los análisis dedicados a fuentes emanadas de instancias civiles. Los trabajos aparecidos recogen documentación episcopal, capitular, catedralicia, monacal... pero casi nada se ha hecho, salvo honrosas excepciones, sobre los testimonios medievales conservados en los municipios abandonados muchas veces a su suerte y en condiciones lamentables de conservación». Quiero detenerme un momento para subrayar no sólo lo verídico de las afirmaciones anteriores, sino sobre todo para destacar las últimas palabras: «en lamentable estado de conservación». La UNED, con un distrito universitario nacional y con un sistema docente peculiar, me ha obligado o permitido recorrer los más variados lugares de nuestra geografía. En ocasiones he podido visitar algunos, usemos la terminología académica, archivos municipales en los que el estado de abandono de la documentación histórica era total y otro tanto pasaba con los fondos documentales de algunas iglesias parroquiales. Esta situación me proporcionó la idea de proponer un curso de doctorado consistente en organizar, inventariar, y/o catalogar los fondos documentales, hasta el siglo XVI, existentes en su lugar de residencia. La idea era correcta: los alumnos de la UNED residen en ciudades, villas, pueblos o aldeas; los archivos del lugar están a su alcance y en muchas ocasiones forman parte del legítimo orgullo provinciano. Los resultados están siendo satisfactorios, al menos los archivos se están organizando.

Volvamos a San Bartolomé de Pinares. Conserva este municipio un total de 90 documentos anteriores al año 1500 mientras que la data del más antiguo es de 1274 y el primer original es de 1327 . Hay 13 diplomas reales y más de 20 emanados de distintas instancias de la Mesta: concesiones, confirmaciones, requerimientos, procuraciones, sentencias, deslindes,... a lo que hay que añadir un amplio número de documentación particular y concejil, entre la que cabe destacar: correspondencia, procuraciones, avenencias, contratos de censo, contratos de obras, toma de 
posesión...; no se conservan las ordenanzas municipales, ni documentación relativa a los repartimientos. Un tipo documental se repite constantemente: los deslindes. En toda esta documentación se pone de manifiesto hasta donde se deja sentir la influencia de las directrices y actuaciones de dos instituciones, la Mesta y el concejo de Ávila, cabeza de la comunidad de Villa y Tierra, en ámbitos tan reducidos como el correspondiente a un concejo aldeano; aparecen, asimismo, aspectos de la organización concejil, preocupaciones generales, enfrentamientos entre vecinos, rivalidades con los núcleos de población colindantes, las dificultades recaudatorias o las presiones usurarias y las dificultades para hacer frente a las devoluciones.

LUIS LóPEZ, Carmelo, Colección documental del Archivo municipal de Piedrahita. 1372-1549. Ávila 1987.

El archivo concejil de Piedrahita, en contra de algunas opiniones dadas a conocer en publicaciones no tan antiguas, es el más importante de época medieval dentro de la provincia de Ávila, tanto por la abundancia como por la variedad de sus fondos.

Toda su documentación tiene como soporte material el papel, salvo tres piezas: dos en sendos pergaminos sueltos y un cuaderno, también de pergamino, con la recopilación de las ordenanzas municipales redactadas el año 1509.

A veces, sólo a veces, ocurre que algunas villas han mostrado un encomiable celo por conservar la documentación preparada y expedida por sus instituciones o recibida por estas, documentación que a la postre se convierte en inestimable cuando se pretende recordar con veracidad el pasado glorioso a no tan glorioso. Es este el caso de Piedrahita, cuyo archivo histórico municipal, custodia documentos propios desde el año 1372. Este primer documento se refiere a un "amojonamiento y fijación de límites de propiedades entre las villas de Piedrahita y Villafranca de la Sierra». Este tema y en estas o en fechas próximas a estas, como hemos visto, se repite de forma continuada en todos los concejos abulenses cuya documentación conocemos. La fijación de límites daba ocasión siempre a la elaboración de un documento de carácter jurídico que debía de ser guardado celosamente por los concejos implicados, puesto que era garante de sus derechos en caso de nuevos litigios o discusiones entre los contendientes; nada tiene de extraño que este tipo documental aparezca con reiativa frecuencia entre los conservados por los concejos, 
aparte de que desde la óptica histórica tengan otras muy varias interpretaciones: nobleza usurpadora, debilidad concejil, gastos cuantiosos para el concejo en interminables pleitos, representantes concejiles en camino de ida y vuelta a las audiencias reales, búsqueda de valedores en la corte por cada una de las partes litigantes, carta de poder de los concejos para sus procuradores y comisionados, $\ldots$ etc.

Otros tipos documentales abundan en este archivo de la villa: libros de provisiones, libros de acuerdos del concejo, los llamados libros del Becerro de las Ordenanzas cuyo contenido es: ordenanzas, privilegios, provisiones, nombramientos, «vecindades». Para aquellos a quienes interese lo económico, se conservan también: cuadernos de cuentas, cuentas de ingresos y gastos del concejo, expedientes de pleitos, cuentas de obras, escrituras de compraventa del concejo, repartimientos,... etc. En general se puede afirmar que existen abundantes noticias sobre la administración concejil de una comunidad de Villa y Tierra, así como un esquema de funcionamiento de una sociedad agraria en zona de montaña y con una situación geográfica muy concreta. Se conserva también documentación señorial y hasta un "cuadernillo de cuentas del duque de Alba».

Como documentación preparada y expedida por una institución de carácter público, es predominante la imagen de una vida estructural en detrimento de la vida ordinaria de una villa medieval; será necesario por tanto interrogar adecuadamente a estas fuentes y realizar análisis comparativos, no sólo sobre la propia documentación, con sus variantes o afinidades tipológicas, sino también sobre las cuestiones que en ella se plantean, para poder llegar más allá de lo que nos permiten las noticias que una primera lectura nos puede proporcionar.

Monsalvo Antón, José María, Crdenanzas medievales de Ávila y su Tierra. Ávila 1990.

Hace algunos años el Profesor Miguel A. LAREdo QueSADA publicó un interesante artículo sobre la importancia de las ordenanzas para el conocimiento de nuestro pasado; acompañaba a esta publicación un inventario de todas las normativas locales publicadas hasta aquella fecha ${ }^{13}$.

13 Ladero Quesada, Miguel Ángel. «Las ordenanzas locales en la Corona de Castilla como fuente histórica y tema de investigación (siglos XIII al XVIII) en Revista de Estudios de la vida Local, año XLIl-número 217 enero-marzo 1983. Madrid, pág. 85-108. 
Las Ordenanzas medievales de Ávila fueron publicadas por MOLINERo y por el Marqués de FORONDA; ahora se publican las ya conocidas con algunas correcciones y con nuevas aportaciones. Se publican sólo los textos legales en su categoría de fuente histórica y el propio autor, el Profesor Monsalvo Antón, promete un estudio técnico de estos documentos jurídico-normativos.

El conjunto de ordenanzas abulenses de 1487 son, a juicio de Corral García, "el más extenso y completo de los que conocemos en Castilla en esas fechas y la primera gran recopilación»; añade que "destacan por su gran extensión y contenido, impropio de su época».

La documentación para el estudio de las ordenanzas abulenses se encuentran en el Archivo Municipal de Ávila, en el Archivo Histórico Provincial de Ávila y en el Archivo del Asocio de la Universidad y Tierra de Ávila.

El texto de 1487 es una recopilación de normas de derecho local que debemos considerar como resultado de una larga elaboración que parece que tuvo sus comienzos a mediados del siglo xV. La génesis ha sido larga y sectorial: la primera ordenanza fue "sobre panes y viñas" y otras materias afines que pudieran haber sido elaboradas hacia 1346; por ellas se regulaban las cuestiones relacionadas con la esfera agropastoril. El segundo grupo está dedicado a la reglamentación del mercado local, los abastecimientos, la verita y elaboración de productos..., etc. que pueden llamarse "ordenanzas de "fieles"», porque estos eran los oficiales del consejo encargados de ejercer el control directo de este tipo de asuntos. A partir de estos dos textos básicos, una comisión reunida en 1485 y compuesta por todos los "estados" de Ávila y su Tierra: regidores y caballeros, representantes de los pecheros y del estamento eclesiásti$\mathrm{co}$, con los letrados del consejo, elaboraron el texto que conocemos. Su lectura da lugar a la sospecha de que en la elaboración de esta recopilación de ordenanzas debieron existir momentos de tensión; en concreto los escribanos de número, asociados en cabildo, presionaron sobre la comisión a fin de conseguir un aumento de los derechos a cobrar por diversos tipos de escrituras; consiguieron que aigunas escrituras fueran mejor tasadas por las ordenanzas ${ }^{14}$.

${ }^{14}$ Casado Quintanilla, Blas. "Autenticidad documental y escribanos de Ávila en la Baja Edad Media" en Espacio Tiempo y Forma, Serie III, Historia Medieval, Homenaje al Prof. Eloy Benito Ruano. Madrid, 1988, pág. 175-192.

(Casado Quintanilla, Blas, "Escribanos de Ávila en la Baja Edad Media", Espacio, Tiempo y Forma, IV, 1989) 
Estas ordenanzas proporcionan abundantes datos sobre la organización administrativa y territorial, sobre la administración de justicia, sobre la economía rural, el paisaje agrario, el trabajo agricola: cultivos, formas y normas de explotación, aprovechamiento pastoril privado y comunal, protección de sembrados y zonas forestales. Se regulan, también, la artesanía, la circulación de mercancías, oficios urbanos, pesas y medidas. No faltan las normativas sobre asuntos urbanísticos: limpieza de las calles y plazas, edificaciones, y otros aspectos no menos importantes de la vida diaria: juegos, moralidad y orden público, uso de la pólvora..., etc. A la postre se encuentra una regulación casi exhaustiva del desarrollo de la vida laboral tanto en cosas puntuales como en su carácter cíclico, porque cíclica es la labor agrícola, su principal actividad, junto con el comercio.

LUIS LóPEZ, Carmelo y SER QUIJANo, Gregorio del, Documentación medieval del Asocio de la Extinta Universidad y Tierra de Ávila, I, Ávila 1990.

Molinero Fernández, en su Estudio Histórico del Asocio de la Extínta Universidad y Tierra de Ávila, Ávila 1919, dice: «Desde tiempos muy remotos vienen gozando la ciudad de Ávila y los pueblos asociados de su tierra, en plena propiedad, de vastísimos terrenos destinados a monte, labor y pastos... la comunidad formada por esta ciudad y sus pueblos ha sido denominada Universidad y Tierra y su finalidad es el aprovechamiento "comunal’ de los montes, pastos y tierras de labor enclavados en el territorio por ellos ocupado". Señala también el autor el sistema de formación de estas extensas propiedades que "han sido adquiridos por derechos de conquista, por cesiones hechas a los mismos por varios monarcas y por ventas realizadas en distintas épocas a esta comunidad». El origen hay que buscarlo en los años próximos a los de la repoblación de la ciudad y su tierra, debido al conde Don Raimundo de Borgoña y realizada a finales del siglo XI. Se pobló entonces la ciudad, en la que se nombraron las autoridades correspondientes y se fue repoblando su álfoz, donde también se crearon concejos y autoridades, dependientes de los alcaldes y alguaciles de la ciudad. Tanto a una como a otros se les señalaron los términos de tierras de labor, pastos y montes y en estos amojonamientos y dependencia administrativa inicial de los pueblos respecto de la ciudad hay que buscar el origen del Asocio.

Esta comunidad de propiedades perduró en su integridad hasta la desamortización, y aun existe en la actualidad, aunque muy reducida en sus posesiones y en su actividad. 
Su dilatada existencia ha dado origen a una copiosa documentación como fruto de las normales tareas de su administración. A éstas hay que añadir los abundantes documentos producidos a causa de las rivalidades entre los pueblos y la ciudad y entre estos, ciudad y pueblos, y algunos caballeros abulenses que pretendieron ampliar su patrimonio personal o familiar a costa de los bienes del asocio. Estas diferencias dejaron su huella en numerosos pleitos, procuraciones, cartas de poder de los pueblos y de la ciudad a sus representantes en los litigios para defender sus negocios, pesquisas, amojonamientos, tomas de posesión, sentencias y recursos.

Toda esta documentación de carácter jurídico y administrativo, se conserva en el archivo del Asocio. Es fácil suponer que este tipo de organizaciones exige un especial cuidado de sus administradores para conservar los instrumentos jurídicos que garantizaban los derechos, la propiedad y la amplitud de las obligaciones de las partes integrantes 0 terceros; máxime si, como sabemos, los litigios eran abundantes. Sus fondos eran conocidos sólo en parte por las publicaciones de MOLINERO FERNÁNDEZ; ahora ve a la luz en su integridad, aunque sólo ha salido el primero de los volúmenes de este título. Muchos de estos documentos se conservan en copias posteriores y casi siempre se debe a razones judiciales.

Si hiciéramos un cómputo cronológico de los fondos conservados volveríamos a confirmar aquello que dijimos más arriba: se confirma su irregular distribución a lo largo del período medieval; se conservan sólo tres documentos del siglo XII; 20 son del siglo XIII; al siglo XIV le corresponden 30 y aumenta considerablemente la proporción en todo el siglo $\mathrm{xv}$, especialmente en el último cuarto de la centuria.

\subsection{Archivos Eclesiásticos}

Al principio de esta exposición habíamos indicado que para hacer un correcto análisis de los documentos era necesario "saber interrogarlos". Una de las primeras preguntas consistirá en buscar las razones por las cuales un documento fue preparado y expedido por la institución o persona titular del mismo. Hemos de partir del hecho cierto de que ningún documento ha sido producido gratuitamente tanto si es auténtico como si es falso, y menos aún en este segundo supuesto. La respuesta a este interrogante, en los casos en que se obtenga, será de muy variado contenido; al historiador corresponde estructurar adecuadamente la información así obtenida. Por nuestra parte en este epígrafe sobre los archivos 
eclesiásticos queremos destacar un aspecto: el titular de un documento medieval puede ser un rey, un señor, un concejo, un obispo, un cabildo..., etc. En un tanto por ciento muy elevado de los documentos emanados por cada uno de las instancias de poder señaladas, sean eclesiásticas o civiles, aparecen suscripciones de personas eclesiásticas, bien porque forman parte de la cancillería real o de los consejos regios o bien porque han intervenido en la «actio», cuya expresión es el documento que conocemos. La superposición de lo eclesiástico y lo civil en la elaboración de los documentos no deja lugar a dudas sobre la relación entre la instancia civil y religiosa. Para llegar a un mejor conocimiento, para conseguir una mejor lectura de los documentos medievales, aunque éstos sean de origen civil, será necesario atender a los fondos conservados en los archivos eclesiásticos. Tambien estos han sufrido el deterioro propiciado por el tiempo o por el abandono, pero conservan grandes e importantes fondos, fondos que sería muy cuestionable calificarlos de eclesiásticos. De una parte, en estos archivos hay un porcentaje documental muy importante de titularidad eclesiástica pero que por estar destinados a gobernar o administrar un señorío, pierden aquel significado y adquieren otro vinculado con personas que forman la sociedad que hoy calificaríamos de civil. De otra parte «un archivo catedral, diocesano, parroquial o monástico, en un tanto por ciento muy considerable de casos, además de los producidos por estas instituciones, ha ido enriqueciendose a base de anexionar al nucleo original del mismo, otros archivos particulares correspondientes a un predio, a una finca que constituía la dote de una determinada donación", acción esta de las donaciones ampliamente documentada a lo largo de la edad media, aunque más en unas épocas que en otras, como se ha demostrado. En cualquier caso, puesto que los documentos eran los títulos de propiedad de determinados predios y otras posesiones, las donaciones llevaban aparejado la entrega de estos títulos de propiedad a la institución beneficiaria, de ordinario institución eclesiástica o asimilada y "a medida que estas donaciones iban creciendo, aumentaban considerablemente el número de documentos del archivo principal, documentos de la más rara y variada procedencia» que obligaban a visitar los fondos eclesiásticos para los más variados temas.

Siguiendo la pista de lo económico-administrativo, que ocupa el tiempo de muchos historiadores actuales, Angel FABREGA GraU, afirma que "nadie me tachará de optimista si afirmo que tres cuartas partes del volumen documental de los archivos eclesiásticos, desde el siglo Ix hasta el XX, pueden reducirse a la categoría de fuentes documentales de caracter económico-administrativo". Nada tiene esto de extraño para los que conocen un poco la Edad Media y no olvidan el mundo feudal y el sistema beneficial. La iglesia, integrada plenamente en el sistema, produjo 
importantes series documentales de esta actividad, posiblemente no más que la alta nobleza, pero con alguna diferencia de interés documental: en la iglesia y en las instituciones eclesiásticas no existen herederos individuales, sino que la institución hereda a la propia institución por generaciones y generaciones. Mientras que el sistema de herederos individuales dificulta la conservación de los documentos y facilita la dispersión, la pérdida y hasta la incuria documental; el sistema eclesiástico favorece su conservación, aunque, debido a múltiples causas, no ha sucedido siempre así.

Todavía podemos señalar algunas cuestiones en las que la consulta a los archivos de la iglesia reviste importancia especial. Las llamadas series de "fábrica" o de "obra" de una catedral o iglesia no puede estudiarse sin acudir a estos archivos. En estos conjuntos documentales, aunque el predominio de noticias artísticas es manifiesto, ello no significa que un atento lector no pueda conseguir datos de muy variados aspectos sociales, culturales, económicos..., etc. No queremos olvidarnos de la documentación originada por los notarios eclesiásticos: quizás no sea tan importante en las ciudades bien estructuradas y dotadas de notarios civiles abundantes en las que estos realizaban casi todo el trabajo de notaría que acaeciera, cuanto en los núcleos de población menos importantes, donde el sacerdote, posiblemente el único que conocía el arte de escribir, ejercía de notario. Quiero llamar la atención en este apartado a la acción de poner por escrito los testamentos en aquellos lugares a los que no llegaban los notarios, llamémoslos oficiales, lugares en los que los sacerdotes ejercian de tales y que se guardaban en los archivos parroquiales, que en buena lógica debieron de ir a parar a los archivos diocesanos. Conectado con este punto, hemos de hacer referencia a los "libros sacramentales", aunque su existencia, vinculada al concilio de Trento, nos lleve a ese siglo xvı al que los medievalistas no dedican su atención investigadora.

Aparte otras consideraciones como que la iglesia ha sido una estructura de poder muy significativa en la Edad Media, tanto en lo económico como en lo político, no cabe la menor duda que en la cultura humana occidental se ha dado una imbricación de lo religioso y lo civil. "Quien quiera ahondar en el conocimiento de los acontecimientos de la iglesia en el pasado no puede prescindir de los archivos civiles, y el que quiera tener un conocimiento lo más exacto posible del acontecer de la sociedad civil, necesariamente habrá de consultar los archivos de la iglesia». Cuanto más antiguo es el período que se quiere estudiar, mayor es la necesidad de acudir a los archivos eclesiásticos, especialmente los monásticos, que son mucho más antiguos que los archivos civiles. Entendemos por documentos, también, todo el tesoro de códices y otros fon- 
dos procedentes de la actividad, propia de los grandes centros monásticos, donde un grupo de copistas nos dejaron un extraordinario legado cultural y artístico; sin que podamos olvidarnos de las muy interesantes reproducciones de la vida medieval, de sus creencias religiosas, sobre la naturaleza o sobre la propia sociedad, rudimentarias unas, perfectas otras, a través de las miniaturas que embellecen los códices conservados.

Sobrino Chomon, Tomás, Documentos de antiguos Cabildos, Cofradías y Hermandades abulenses. Ávila 1988.

La ordenanzas del cabildo abulense en la Baja Edad Media, tienen sin duda un gran valor para el conocimiento de la historia de la iglesia provincial, al menos en su vertiente estructural, sin que este texto normativo excluya otros temas de interés histórico general.

Creo que es de mayor interés y actualidad el conocimiento de los estatutos de Hermandades y Cofradías ligadas a la muerte y la beneficencia; ambos aspectos de la vida y la sociedad medieval que últimamente están siendo ubjeto de atención para muchos historiadores. En todas estas asociaciones de gran arraigo popular, cuya permanencia puede rastrearse hasta no muchos años atras, aparece la obligación de solemnizar y acompañar a los difuntos que hayan sido miembros de la cofradía "porque principalmente para esto fueron fundadas las hermandades, para enterrar a los difuntos y honrrarlos y para pagar las obras de misericordia" según señalan las ordenanzas de Nuestra Señora de Sonsoles en su art. 48.

Se contempla, también, el acompañamiento de los cadáveres de los pobres y ajusticiados, entre las obras de beneficencia. "Sensu contrario" cabe pensar que a no ser por esta obligación moral contraída por pertenecer a una cofradía o hermandad, muchos difuntos irían casi en solitario camino del cementerio.

En cuanto a lo que antes decíamos de solemnizar el enterramiento, estas cofradías alquilaban sus servicios, si algún otro cadaver, se supone de persona destacada de la sociedad lugareña, quería ser acompañado. En estos casos la hermandad o cofradía cumplía con lo que se le pedía mediante el pago de un fuerte estipendio para la hermandad, mediante un contrato en el que el mayordomo se curaba en salud tomando incluso fianzas para evitar el fraude. 
En lo referente a la beneficencia, se prescribe la ayuda mutua en las necesidades de pobreza o enfermedad; la cofradía se obligaba a velar durante la noche al enfermo grave, e incluso, a pedir para ayudar económicamente a quien pasare necesidad; se refiere principalmente entre miembros de la misma cofradía o hermandad.

Estos documentos sobre cabildos, cofradías y hermandades religiosas, son ordenamientos jurídicos con vigencia temporal; esta temporalidad lleva consigo la renovación, incluso, frecuente de todos o algunos de los artículos. Cada vez que se reformaban, aunque permanecieran fieles a los principios básicos, se hacía una nueva copia y se despreciaba la antigua porque ya no servía y su destino era bien la destrucción material o bien pasaba a manos de algún miembro de la directiva de la asociación y con el tiempo se perdería.

Interesa finalmente destacar que la mayoria de las ordenanzas de cofradias o hermandades de ámbito rural, también las hay urbanas, están redactadas por hombres del pueblo o por clérigos rurales no muy letrados, quienes han dejado su huella en el excesivo vulgarismo de su redacción. Este vulgarismo puede ser despreciado desde una óptica cultista, pero favorece al historiador quien, por la vía de la filología, puede acercarse al modo usual de expresarse en los pueblos y villas en las que se elaboraron estas ordenanzas.

Barrios García, Angel, Documentación medieval de la catedral de Ávila. Universidad de Salamanca, 1981.

Se publican aquí documentos emanados de la escribanía catedralicia, recibidos en esta iglesia o suscritos entre particulares que fueron a engrosar, por vías muy diversas, el archivo originario de la catedral. Estos documentos, que sirvieron de fuente histórica para la elaboración de la tesis doctoral del autor, tienen un gran interés para el conocimiento de la iglesia abulense; sirven también para demostrar una vez más que los archivos eclesiásticos, así llamados por el origen, destino o lugar de conservación de ciertos fondos, por su contenido histórico, en cambio, están estrechamente vinculados a la sociedad de su tiempo, tanto en lo civil como en lo eclesiástico; son inestimables para el conocimiento de las formas de vida de los hombres medievales de la zona donde se produjeron. 
Si en un primer momento se reunieron en este archivo de la catedral, independientemente de su origen, otros acontecimientos del pasado histórico, bastante más cercanos a nosostros de los que se indica en la data de los documentos conservados, sirvieron de causa para su dispersión: se conservan algunos en el archivo de la catedral de Ávila; otros en el Archivo Histórico Nacional de Madrid, en la sección de clero; otros en la sección de manuscritos de la Biblioteca Nacional de Madrid. El archivo Vaticano, cómo no, también es un lugar de visita obligada.

Los fondos archivísticos que se publican en este volumen empiezan en el año 1130, con una donación del Alfonso VII a la catedral de Ávila y alcanzan hasta 1300; a estos documentos sueltos hay que añadir un códice, llamado "Becerro de Visitaciones» que es una relación detallada de las propiedades de la catedral de Ávila en 1303, con descripciones, a veces minuciosas, de algunas de estas posesiones abarcando los más variados asuntos culturales socioeconómicos hasta el punto de que el propio autor afirma que las ha «utilizado como fuente básica en nuestra tesis doctoral»".

Los fondos conservados de archivos civiles, en esta como en otras ocasiones, son superados en antigüedad por los eclesiásticos; en el caso de consejo abulense un acontecimiento bélico entre los ejércitos de Pedro I y Enrique II en 1368, dio ocasión a que las tropas inglesas que apoyaban la causa del primero quemaran las casas donde se conservaba la documentación concejil.

Barrios García, Angel, «Documentación de San Clemente de Adaja. Siglos XIII y XIV», en Cuadernos Abulenses, I, (1984), págs. 91-139.

Aun en los casos en que aparece un solo autor de la transcripción hay que destacar la formación de un equipo de trabajo quien de previo acuerdo se distribuyó la tarea de la transcripción de los fondos documentales.

Es necesario indicar, para situarnos debidamente, que sería totalmente infructuoso pretender visitar otro monasterio más en Ávila: el monasterio de San Clemente no existe. Este se fundó a principios de siglo XIII, extramuros de la ciudad al otro lado del río Adaja. El año 1331 el obispo abulense Sancho Blazquez Dávila «catando en cómmo el monasterio de las monjas de San Clemeynte de Allend del Adaja de Ávila de la orden del Cistel, estava perdido e destruydo, assí en las moradas 
que en él solían ser e agora eran, conmo en los algos» había construido en el arrabal norte de Ávila el monasterio de San Benito, después llamado de Santa Ana, a donde llevó a las monjas del ruinoso convento de San Clemente. BArRios, Angel, obr. cit. Cuadernos Abulenses, I, (1984), pág. 93. Pocas señales quedan de la existencia de este monasterio de San Clemente, pero si las autoridades competentes lo permiten y pagan la puesta en práctica de ese permiso, los arqueólogos podrán, en su momento, situar con exactitud y describir este antiguo centro monástico abulense.

Queremos destacar algunas carácteristicas de este conjunto documental. El autor de las transcripciones, siguiendo el criterio de H. Grassotti, califica de falsos algunos de los documentos que presenta. Yo no voy a definirme repecto de estas falsificaciones, porque no he tenido ocasión de ver los diplomas en cuestión. Se trata de unos documentos en los cuales el concejo abulense hace unas donaciones at monasterio en el año 1281 y de las posteriores confirmaciones de este mismo documento por parte de la cancillería de los reyes sucesivos. Si la falsificación en el ámbito concejil pudiera llamar la atención, mayor interés tiene el afirmar que la cancillería real dio por válido un documento falso en varias ocasiones: 1282, 1290, 1298 y 1332.

Otro aspecto de interés son las noticias según las cuales el concejo de Ávila favoreció a este monasterio: con donaciones de heredades, con el privilegio de cortar en su pinar cuanta madera necesitaran, con la libertad de pastos para los ganados del monasterio...; el propio concejo abulense establece a favor de este monasterio el impuesto llamado de las "cuartillas". Consistía este gravamen en que todo hombre que labrase con bueyes, tanto en la villa, como en el alfoz, pagara cada año al monasterio una cuartilla de trigo. Concede también el concejo una cuantía de maravedis para la construcción del nuevo convento de San Benito, después llamado Santa Clara.

Barrios García, Ángel, "Catálogo de la documentación de los archivos municipales abulenses. (Siglos XVII-XIV, en Studia Historica (Historia Medieval), V, (1987), págs. 197-251.

Para finalizar este estudio de los volúmenes de fuentes abulenses publicadas, vamos a detenernos en otra publicación distinta de las demás. Como el mismo título indica se trata de un catálogo que permite conocer en qué municipios se conserva documentación de los siglos me- 
dievales en qué municipios de lugares que en esta época tuvieron gran importancia no se han conservado. La escasez de documentación medieval conservada es la nota más característica. Se conserva documentación de carácter civil en los archivos municipales de: La Adrada, Bonilla de la Sierra, Candeleda, Higuera de las Dueñas, Mombeltrán, Piedrahita, Ríofrío, San Bartolomé de Pinares, El Tiemblo y por supuesto en Ávila. Importa también destacar la distribución cronológica de los documentos: la primera pieza original es de 1256; el texto más antiguo conservado gracias a sus numerosas copias corresponde al año 1181. Se trata de un diploma por el que Alfonso VIII concede a la ciudad de Ávila el castillo de Castro, en la ribera del Tajo, a la vez que le permite compartir el disfrute de pastos de Campozálvaro con Segovia. 


\section{HISTORIOGRAFIA}

Queremos recoger aquí solamente las publicaciones sobre la historia de Ávila que pueden servir de fuentes y, por lo tanto, son de obligada consulta:

Crónica de la población de Ávila. Anónimo.

Fulgosio, F., Crónica de la provincia de Ávila, Madrid 1870.

FORONDA, Marqués de, "Un códice titulado Crónica de Ávila", $B R A H$, LXII, (1913), págs. 278-283.

Gómez Moreno, M., "La Crónica de la población de Ávila", BRAH, CXIII, (1943), págs. 11-56.

Hernández Segura, Amparo, Crónica de la población de Ávila. Valencia 1966.

Ayora, Gonzalo de, Epílogo de algunas cosas dignas de memoria, pertenecientes a la yllustre e muy magnifica e muy noble ciudad de Ávila. Salamanca 1519.

ARIz, Fray Luis, Historia de las grandezas de la ciudad de Ávila. Alcalá de Henares 1607. Ávila, edición facsímil de la Caja de Ahorros de Ávila, 1978.

Ballesteros, Enrique, Estudio histórico de Ávila y su territorio. Ávila 1896.

Martín Carramolino, Juan, Historia de Ávila, su provincia y obispado, 3 vols., Madrid 1872.

Molinero Fernández, J., Estudio histórico del Asocio de la extinta Universidad y Tierra de Ávila. Ávila 1919.

Montalvo, J. J. de, De la historia de Arévalo y sus sexmos, 2 vols., Valladolid 1928.

Los que estén interesados en disponer de un bibliografía más amplia sobre Ávila, aparte de otras obras, pueden consultar las siguientes: 
Sobrino Chomom, Tomás, voz "Ávila», en Diccionario de Historia Eclesiástica de España, I, Madrid, (1972), págs. 156-162.

BarRIOS García, Ángel, Estructuras agrarias y de poder en Castilla: el ejemplo de Ávila (1085-1320), I, Ávila 1983.

Belmonte Diaz, José, La Ciudad de Ávila. Estudio Histórico. Ávila, Caja de Ávila, 1987. Recoge toda la bibliografía sobre Ávila. 